Brit. J. prev. soc. Med. (1976), 30, 163-169

\title{
Control of haemolytic disease of the newborn
}

\author{
E. G. KNOX \\ Health Services Research Centre, Department of Social Medicine University of Birmingham
}

\begin{abstract}
Knox, E. G. (1976). British Journal of Preventive and Social Medicine, 30, 163-169. Control of haemolytic disease of the newborn. The decline in the stillbirth and death rates from haemolytic disease of the newborn in England and Wales between 1961 and 1973 is examined. The possible causes for this decline are identified and data related to each are assembled. The effects of intrauterine transfusions, changes in the abortion law, and changes in the racial mix as well as changes in the incidence of toxaemia of pregnancy and caesarean section can probably be disregarded for this purpose. Two major factors are the change in the birth rank distribution of births in England and Wales and general improvements in the quality of perinatal and obstetric care. When the above factors are excluded the effects of the specific control programmes upon stillbirths are not easy to measure or even detect. They probably accounted for less than one-fifth of the total decline in stillbirths from haemolytic disease of the newborn, although probably a larger proportion of the decline in neonatal deaths. During the period concerned, the most effective component in reducing losses was probably in the care of affected live-born infants and the primary preventive programme played only a minor part. Nevertheless, its effects are now discernible and it is likely to play a larger part in subsequent years. The quantification and monitoring of the part played by the preventive programme may require more developed information systems than are at present available.
\end{abstract}

The four main lines of attack upon the problem of haemolytic disease of the newborn (HDN) have been:

1. The immediate diagnosis and the more effective treatment of children born alive with the disease.

2. Induced delivery and subsequent treatment of viable fetuses at high risk of intrauterine death from the disease.

3. Intrauterine transfusion of high-risk fetuses at non-viable fetal ages.

4. Primary prevention of rhesus immunization using immunological methods.

The historical order of development of these approaches is approximately as given. The effect of the first approach was to reduce the number of deaths, of the second and third to reduce the number of stillbirths, of the fourth to reduce first the incidence and subsequently the stillbirth and death rates.
In addition, however, the incidence, stillbirth rate and death rate from HDN may have been influenced by a number of other factors and they include:

1. A changing parity-distribution of births in the population; the incidence and severity of the disease are both greater at higher ranks.

2. Increases in the proportion of births to women of non-European origin; Asian and African women are less often Rh-negative and the incidence of disease is lower in their children.

3. An increase in the frequency of induced abortions and a (hypothetical) increased risk of rhesus immunization before the first full-term birth.

4. The disappearance through the upper end of the reproductive age range of a residue of 
women immunized through blood transfusion in the days before regular and efficient matching were universal.

5. An increased availability of family planning and sterilization procedures, with the opportunity for their selective application to women with histories of severe recurrent fetal disease.

6. Changes in the incidence of caesarean section and toxaemia of pregnancy, both of which are associated with increased rates of rhesus immunization (Knox, 1968; Knox and Walker, 1968).

7. Improvements in the general quality of perinatal obstetric and paediatric care resulting in reduced perinatal deaths from all causes, presumably including those with HDN.

Although primary prevention remains the ideal aim, stillbirths and deaths are the essential problem and only a very small proportion of affected infants survive with disabilities. The evaluation of control programmes can therefore be carried out in terms of deaths and stillbirths and the technical problems are:

1. To ascertain what proportion of observed changes may be attributed to improved medical services as opposed to changing background conditions.

2. To allocate credit within that improvement attributable to medical care, to non-specific improvements, and to the HDN control programme.

3. With respect to the control programme, to allocate appropriate credit to its component parts.

This paper is an attempt to answer these questions through the examination of available national statistics.

\section{Materials AND Methods}

The data on which the analyses are based are drawn from available official statistics, including the Annual and Quarterly Statistical Reviews of the Registrar General for England and Wales and their supplements; the years covered are 1961 to 1973, the period during which causes of stillbirth were registered. The data drawn from this source relate to stillbirths and deaths from HDN. Legitimate stillbirths and total legitimate births are available distributed according to parity, defined as the number of previous live and stillbirths in all marriages. Data on deaths from HDN in live-born infants are also available; these are given distributed (inter alia) according to standard regions in England and Wales, but not by parity. The reports of the hospital in-patient enquiry (HIPE) supplyo sample-based estimates of incidence (Office of: Population Censuses and Surveys and Department of Health and Social Security, 1962-1973).

Annual numbers of abortions carried out orf women resident in England and Wales are provided (since mid-1968) in the Registrar General's Supple ments on Abortion (Registrar General, 1962-1973) Data on total annual births to women born in? 'new Commonwealth' countries are available in the June issues of the Registrar General's Quarterly $\overrightarrow{\mathrm{u}}$ Reviews from 1970 onwards and supplementars evidence relating to the earlier years is available ita Social Trends, a publication of the government statistical service.

The methods employed consist of the calculation of successive annual rates of occurrence of disease $-\overrightarrow{7}$ death and stillbirth, their distribution wherew appropriate by parity and region, and the execution of simple (indirect) standardization procedures $\vec{D} \overrightarrow{0}$

\section{RESULTS}

Stillbirth rates per 1000 total births and neona留 death rates per 1000 live births, from HDN are given in Table I. They fell steadily for the wholeo of the period 1961-73, except for 1964 when therres was a transient rise. Death rates fell transito during that year, suggesting a transfer of cases from deaths to stillbirths, although the reasons fo릉 such a transfer are not clear. The crude sum of then two rates is also given in Table $I$ and here, the trendo is reasonably regular. The combined value in 1973 was only $39.5 \%$ of that in 1961 , and this is? equivalent to a reduction of $7.5 \%$ per annum? compound.

The incidence of the disease during this period.

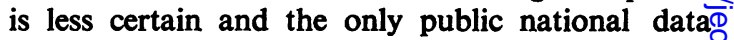
are those based upon the HIPE samples. Estimated? numbers of cases and calculated rates per $1000^{\circ}$ total births are given in Table II. The samples are small, the calculated rates have standard errors of about 0.2 per 1000 , and the data of the early years suggest irregular and incomplete ascertainment. From 1966 onwards the levels are fairly steady, $?$ suggesting that most of the fall in stillbirth and death rates during that time represents improve- N ments in fatality rather than reductions in the rate of occurrence. The rates are still lower than more
direct estimates suggest.

The ratio between the stillbirth and death rates remained fairly constant throughout the 13-yearo period. An increasing tendency to induce early delivery in cases of anticipated intrauterine death? 
TABLE I

STILLBIRTHS AND DEATH RATES PER 1000 BIRTHS FROM HDN IN ENGLAND AND WALES

\begin{tabular}{|c|c|c|c|c|c|c|c|c|c|c|c|c|c|}
\hline \multirow[b]{3}{*}{ Stillbirth rate } & \multicolumn{13}{|c|}{ Year } \\
\hline & 1961 & 1962 & 1963 & 1964 & 1965 & 1966 & 1967 & 1968 & 1969 & 1970 & 1971 & 1972 & 1973 \\
\hline & 0.90 & 0.79 & 0.76 & 0.82 & $0 \cdot 74$ & 0.68 & 0.63 & 0.60 & 0.54 & 0.53 & 0.43 & $0 \cdot 37$ & 0.33 \\
\hline Death rate & $0 \cdot 39$ & 0.41 & 0.39 & 0.25 & $0 \cdot 35$ & $0 \cdot 36$ & $0 \cdot 35$ & 0.30 & $0 \cdot 29$ & $0 \cdot 26$ & $0 \cdot 25$ & $0 \cdot 17$ & $0 \cdot 18$ \\
\hline Sum of above rates & $1 \cdot 29$ & $1 \cdot 20$ & $1 \cdot 15$ & $1 \cdot 07$ & 1.09 & $1 \cdot 04$ & 0.98 & 0.90 & 0.83 & 0.79 & 0.68 & 0.54 & 0.51 \\
\hline
\end{tabular}

Small differences between Table I and Table IV arise from the use of legitimate births in Table IV and all births in Table I

TABLE II

ESTIMATED INCIDENCE OF HAEMOLYTIC DISEASE OF THE NEWBORN IN ENGLAND AND WALES PER 1000 LIVE BIRTHS

\begin{tabular}{l|ccccccccccccc}
\hline & \multicolumn{10}{c}{ Year } \\
\cline { 2 - 11 } & 1961 & 1962 & 1963 & 1964 & 1965 & 1966 & 1967 & 1968 & 1969 & 1970 & 1971 & 1972 \\
\cline { 2 - 11 } Estimated no. & NA & 1808 & 1922 & 2311 & NA & 2873 & 2970 & 2904 & 3216 & 2955 & 2801 & 2609 \\
Rates per 1000 & - & 2.1 & 2.2 & 2.6 & - & 3.3 & 3.5 & 3.5 & 4.0 & 3.7 & 3.5 & 3.6 \\
\hline
\end{tabular}

Note: HIPE data

might have reduced the stillbirth rate only at the expense of raising the death rate through producing numbers of non-viable live-born infants; this does not in fact seem to be the case. Because the ratio has remained constant, and because stillbirths now constitute the major part of losses due to this disease, some of the conclusions drawn from an analysis of stillbirths by parity-this distribution is not available for deaths - can probably be applied to prenatal and postnatal losses jointly.

Table III gives a résumé of stillbirth rates according to the year and to parity. There are some irregularities within this distribution, most of them probably due to small numbers at para-0 and para-4+, but the two main features are clear. They are an increase in stillbirth rates with increasing parity, present in each year, and a decreasing stillbirth rate in successive years, present at each parity. The question arises how much of the overall decline in stillbirth rate displayed in Table I can be explained in terms of a shift in the parity distribution to the left, and how much to the changes in rates within each parity. To answer this question two standardization procedures were carried out upon the rates provided in Table III. The first procedure computed the absolute numbers of stillbirths which would have occurred each year if the parity specific rates for 1961 were applied to the parity distributions in subsequent years. The second procedure reversed the process and calculated the
TABLE III

STILLBIRTH RATES FOR HDN BY YEAR AND BY PARITY: LEGITIMATE BIRTHS ONLY: ENGLAND AND WALES

\begin{tabular}{|c|c|c|c|c|c|c|}
\hline \multirow{2}{*}{ Year } & \multicolumn{6}{|c|}{ Parity (previous live and stillbirths) } \\
\hline & $\mathbf{0}$ & 1 & 2 & 3 & 4 & 5 \\
\hline 1961 & $0 \cdot 15$ & 0.75 & $1 \cdot 68$ & $2 \cdot 16$ & $2 \cdot 23$ & $2 \cdot 35$ \\
\hline 1962 & $0 \cdot 14$ & 0.64 & $1 \cdot 48$ & $1 \cdot 91$ & $2 \cdot 17$ & $2 \cdot 39$ \\
\hline 1963 & $0 \cdot 11$ & 0.66 & $1 \cdot 31$ & $\cdot 1 \cdot 78$ & $2 \cdot 18$ & $2 \cdot 15$ \\
\hline 1964 & $0 \cdot 12$ & 0.76 & $1 \cdot 43$ & $1 \cdot 97$ & $2 \cdot 43$ & $2 \cdot 26$ \\
\hline 1965 & $0 \cdot 11$ & 0.62 & $1 \cdot 53$ & $3 \cdot 18$ & $2 \cdot 06$ & 1.98 \\
\hline 1966 & $0 \cdot 13$ & 0.61 & $1 \cdot 10$ & $1 \cdot 97$ & $1 \cdot 55$ & $3 \cdot 07$ \\
\hline 1967 & $0 \cdot 13$ & 0.54 & $1 \cdot 25$ & $1 \cdot 51$ & $2 \cdot 13$ & $2 \cdot 18$ \\
\hline 1968 & $0 \cdot 10$ & 0.55 & $1 \cdot 37$ & $1 \cdot 28$ & $1 \cdot 70$ & 1.99 \\
\hline 1969 & 0.08 & 0.56 & $1 \cdot 17$ & $1 \cdot 61$ & 1.43 & $1 \cdot 57$ \\
\hline 1970 & 0.12 & 0.40 & $1 \cdot 25$ & $1 \cdot 16$ & $1 \cdot 85$ & 1.57 \\
\hline 1971 & 0.07 & 0.32 & 1.02 & $1 \cdot 24$ & $1 \cdot 63$ & 1.73 \\
\hline 1972 & 0.07 & 0.29 & 0.95 & $1 \cdot 16$ & $1 \cdot 45$ & $1 \cdot 23$ \\
\hline 1973 & 0.08 & 0.24 & 0.66 & $1 \cdot 49$ & $1 \cdot 25$ & 1.03 \\
\hline
\end{tabular}

expected numbers assuming that the relative parity distribution of 1961 remained constant while the rate within each birth rank changed as observed. The results of the standardization are shown in Table IV. 
TABLE IV

OBSERVED STILLBIRTHS FROM HDN AND STANDARDIZED EXPECTATIONS

\begin{tabular}{c|cc|cc}
\hline \multirow{2}{*}{ Year } & \multicolumn{2}{|c|}{ Observed Stillbirths } & \multicolumn{2}{c}{ Expectations } \\
\cline { 2 - 5 } & \multicolumn{2}{|c|}{ No. } & Rates & \multicolumn{2}{|c}{ 1961 Parity* 1961 Rates $\dagger$} \\
\hline & & & & \\
1961 & 720 & 0.95 & 0.95 & 0.95 \\
1962 & 647 & 0.83 & 0.82 & 0.95 \\
1963 & 640 & 0.81 & 0.79 & 0.96 \\
1964 & 708 & 0.87 & 0.85 & 0.97 \\
1965 & 622 & 0.78 & 0.90 & 0.95 \\
1966 & 559 & 0.72 & 0.73 & 0.93 \\
1967 & 505 & 0.67 & 0.69 & 0.90 \\
1968 & 473 & 0.64 & 0.67 & 0.89 \\
1969 & 424 & 0.59 & 0.63 & 0.87 \\
1970 & 392 & 0.55 & 0.61 & 0.85 \\
1971 & 313 & 0.44 & 0.52 & 0.82 \\
1972 & 258 & 0.40 & 0.48 & 0.80 \\
1973 & 198 & 0.33 & 0.43 & 0.75 \\
\hline
\end{tabular}

*1961 proportional parity distribution is held constant, the calculations being otherwise based upon observed total numbers of births and observed parity-specific rates

†The 1961 parity specific rates are held constant and applied to observed absolute births at each parity

Both sets of expectations showed a downward trend between 1961 and 1973 and each factor alone accounts for a substantial fall. Most of the parity-shift effect appeared in the last few years, while the changes due to altered rates were more evenly progressive. The overall changes attributable to improvements in rates are more substantial than those attributable to the demographic changes. The two trends, calculated in this way, are not simply additive and their relationship can be expressed in different ways, but we might say that parity changes accounted for $38 \%$ of the total observed decline while the rate changes, considered as a marginal effect, accounted for the remaining $62 \%$.

The effects of two social changes were then examined, namely the change in the law on abortion and changes in the racial mix of births. Numbers of abortions performed upon women resident in England and Wales in successive years are given in Table V. The numbers may have increased too late in the period of observation to produce any large effect, although many thousands of women, by 1973 , must have been eligible for entry into the early columns of Table III. The main effect, if any, would be upon incidence, for which we do not have accurate national data, but there might also have been an effect upon stillbirth rates occurring at first deliveries (para-0). In fact there is no suggestion here of an increase and it is concluded that the effect of abortions may for present purposes be ignored.

Blood group distributions in Asian and African women are quite different from those of western Europeans. Very few Asians, for example, are Rh-negative compared with about $15 \%$ of European
TABLE V

NOTIFIED ABORTIONS PERFORMED ON WOMEN RESIDENT IN ENGLAND AND WALES

\begin{tabular}{cccccc}
\hline \multicolumn{6}{c}{ Year } \\
\hline 1968 & 1969 & 1970 & 1971 & 1972 & 1973 \\
\hline 22352 & 49829 & 75962 & 94570 & 108565 & 110568 \\
\hline
\end{tabular}

Figures for 1968 are for eight months only

women. Data were therefore sought regarding the $\vec{\circ}$ proportions of births to women of Asian andAfrican ethnic groups during the period concerned. $\vec{\omega}$ Between 1969 and 1973, for which figures are? available, the proportion did not vary outside the range $5 \cdot 1$ to $5 \cdot 9 \%$. An indication of rates in previous years can be obtained from the proportions. of schoolchildren whose parents are of 'new'Commonwealth' descent. Children who were between $\mathscr{C}^{\circ}$ five and nine years old in 1974, that is were borno between 1965 and 1960 , comprised $4.6 \%$ of the total. Children five years older, born in the periodes 1960 to 1964 , comprised $4.0 \%$. It would therefoged appear that the proportion of European births fild by not more than $1.5 \%$ during the period 1961 . 1973 , and it would therefore be reasonable to $\frac{\text { C }}{-}$ attribute not more than $1.5 \%$ of the fall in HD\& $\overrightarrow{6}$ death rate and stillbirth rate to this cause.

The separation of the non-demographic com: ponent of recent trends into that part attributable to measures specific to $\mathrm{HDN}$, and that part attributable to more general improvements in perinatal and obstetric care is a more difficult $\frac{\circ}{\mathrm{D}}$ problem. Between 1961 and 1973 the stillbirth rate $\stackrel{\varrho}{\overrightarrow{2}}$ from all causes in England and Wales fell from 0 19 to 12 per 1000 total births, a reduction of $37 \%$. There were some small variations according to cause of stillbirth, but not a great deal, and the parity distributions of all stillbirths are not such as to account for these falls in the same way as in HDN. ? The non-demographic component of the fall in $\frac{5}{3}$ the HDN stillbirth rate $(37.5 \%$ in 13 years) did

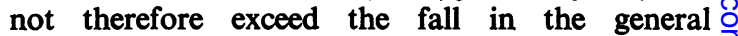
stillbirth rate by any measurable amount, and although this does not allow for interpretation in $\frac{\text { o }}{3}$ exact numerical terms it must be concluded that a $>$ major part of the decline in HDN stillbirths resulted from non-specific improvements, rather than specific $\bar{N}$ curative and preventive measures. In the early years of the period women with rhesus antibodies were $\stackrel{0}{\circ}$ more often admitted to hospital, and to hospitals $\underset{\mathrm{W}}{\mathrm{N}}$ with special care facilities, than were other women 0 and they may have received higher general 0 standards of care. Therefore the scope for $\frac{}{\Phi}$ improvements in stillbirth rate resulting from $\stackrel{?}{+}$ 
non-specific improvements in general perinatal care may not have been as great as in other women. To this extent, there is room within the total picture for some improvements to have resulted from specific measures. Nevertheless, our inability to detect them is disturbing and it is difficult to imagine that specific programmes of care could have resulted in more than one-third of the non-demographic component of the decline.

Three elements of changing patterns of obstetric care can be identified which might have influenced the incidence of HDN, or its fatality rates, with particular effect. They include the availability of surgical sterilization, the incidence of caesarean section, and the incidence of toxaemia of pregnancy. HIPE data for surgical sterilization procedures give estimated numbers of 'divisions and ligations of the oviducts' in England and Wales and the numbers rose from 3898 to 27830 between 1966 and 1972. A change of practice of this order in Rh-immunized women would certainly reduce incidence, death rate, and stillbirth rate. It is possible, although there is no direct evidence, that sterilization procedures may have been applied selectively to $\mathrm{Rh}$-immunized women with homozygous husbands and the most intractable histories of recurrent stillbirths. If so, then this might have reduced stillbirth rates, in particular, to a considerable extent. The incidence of caesarean section, which is a known risk factor for rhesus immunization, has also been changing from 32815 caesarean sections in 1967 to 35764 in 1972. It is unlikely that these small changes could have made any substantial impact upon the incidence of the disease. Finally, numbers of women admitted to hospital with toxaemia have also changed-from 347505 in 1967 to 292905 in 1972. It is difficult to estimate what admission numbers of these orders mean in terms of actual morbidity changes, but they would not be expected to reduce the incidence of HDN by more than a few per cent. It may probably be concluded that on balance these three changes in obstetric practice reduced the incidence of birth and death rates, but not to a degree sufficient to affect estimates of the main effects. That is, demographic and social factors probably accounted for about $40 \%$ of the improvement in stillbirth rates during the 13-year period, general improvements in perinatal care for another $40 \%$, at least, and the specific control programmes for not more than $20 \%$. Indeed, this last credit could be substantially over-generous so far as stillbirths are concerned, although the assessment of deaths is more reliable.

Table III provides some internal evidence to suggest that, although the major part of the decline has been due to other causes, the first returns from the primary preventive programmes are beginning to show. For example, stillbirth rates in para-1 women fell rather sharply after 1969 and those for para-2 women after 1970, and this is the kind of result we would expect from the primary prevention programme.

Table VI gives numbers of issues of doses of immunoglobulin (Maycock, 1975) the smaller doses $(50 \mu \mathrm{g})$ representing in the main the application of immune prophylaxis to abortions, while the larger doses, $200 \mu \mathrm{g}$ up to mid-1971 and $100 \mu \mathrm{g}$ since

TABLE VI

NUMBERS OF DOSES OF ANTI-D (RHO) IMMUNOGLOBULIN ISSUED BY BLOOD PRODUCTS LABORATORY TO REGIONAL TRANSFUSION CENTRES

\begin{tabular}{|c|c|c|c|}
\hline Year & $200 \mu \mathrm{g}$ Antibody & 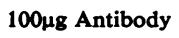 & 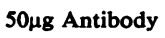 \\
\hline $\begin{array}{l}1967 \\
1968 \\
1969 \\
1970 \\
1971 \\
1972 \\
1973 \\
1974\end{array}$ & $\begin{array}{c}1570 \\
4750 \\
21384 \\
26342 \\
13568 * \\
= \\
-\end{array}$ & $\begin{array}{c}\text { 二 } \\
\text { 二 } \\
37550^{*} \\
76150 \\
72380 \\
66200\end{array}$ & $\begin{array}{c}\text { 二 } \\
\bar{Z} \\
16980 \\
19950 \\
20475 \\
24660\end{array}$ \\
\hline
\end{tabular}

*Dose changed from $200 \mu \mathrm{g}$ to $100 \mu \mathrm{g}$ in May 1971

that time, represent in the main the treatment of women with full-term deliveries. It can be seen that the main increase in the use of this process was between 1969 and 1972 and this would correspond well with the decline in the stillbirth rates observed from 1970 onwards.

Finally, an examination was made of the improvements in the HDN loss rates in the different standard regions of England and Wales. The numbers on which these rates are based are rather small and it is not possible to standardize them for initial and subsequent inter-regional variations in parity distribution. The regions with high loss rates at the beginning of the period (for example, northern, with stillbirth rate of $1 \cdot 25$; north-western, $1 \cdot 03$; eastern, $1 \cdot 11$; compared with England and Wales 0.90) all had higher than average values at the end $(0.45 ; 0.63 ; 0.54$; compared with England and Wales, 0.37 in 1972). There was no evidence of a changed ranking in these respects, related to the different rates of development of the immunological prophylaxis programmes in the different regions. This is consistent with the earlier conclusion that immunological prophylaxis played only a small part in the observed improvements during the period concerned. 


\section{Discussion}

The decline in the death and stillbirth rates from HDN from 1961 to 1973 reflects a period of remarkable therapeutic and prophylactic innovation. The fact that the improvements due to these innovations coincided with improvements attributable to other causes and have been partially masked by them, does nothing to detract from their success. However, it is important for further planning and development of services for this disease, and in deciding appropriate levels of investment, that the whole of the improvement should not be naively attributed to the programmes already undertaken. On the contrary, it is necessary to quantify realistically the improvements attributable to each identifiable cause so that projections of future success can be made, the likely difficulties assessed, and plans laid accordingly.

The analysis presented above shows first that a number of potential effects can be excluded from these considerations, at least in so far as they contributed to changes during the period 1961 to 1973. Changes in the racial mix of the population, increases in the (known) abortion rate, changes in the incidence of toxaemia of pregnancy and of caesarean section, probably played a very minor part. Among the therapeutic procedures, too, fetal transfusion must have had little influence, partly because it was not very frequently performed and partly because it contributes both to the gains (live births) and the losses (stillbirths and neo-natal deaths) of the balance equations used in the analysis.

Two important factors not related to specific HDN programmes however did contribute largely to the fall in stillbirth and death rates for HDN. The first was a shift in the parity distribution of the population and the second was a general improvement in perinatal care resulting in a decline of stillbirths and early deaths from many causes. The first accounted for about $38 \%$ of the decline and the second for much of the remainder. Specific programmes probably accounted for less than $20 \%$ of the total decline in HDN stillbirths.

The relative parts played by the main components of the HDN programme itself are even more difficult to assess. For one component in particular we have almost no data; the increasing use of selective sterilization, abortion, and family planning techniques-as they became more readily available and acceptable-in families with frequent severe HDN can scarcely be quantified at all. Yet the decline in stillbirth rates at high parities, notoriously the location of the most severe and intractable clinical problems, suggests that these procedures must have played their part. Techniques for treating live-born infants improved only marginally? during the 13 years of the survey, but their more effective application must have provided some benefit; mortality from HDN improved more: rapidly than for other causes of neonatal deaths even when an appropriate allowance is made foro changes in parity. By contrast, improved care of the affected fetus, depending upon highly selectives and specific methods of predicting intrauterine deaths, advanced markedly at the beginning of the 13-year period and one might have expected that universal application could have resulted in $a$ sharper decline of HDN stillbirth rates than seems to $\overrightarrow{-}$ have been the case. Unfortunately, there does not appear to be any generally available information. on a national scale for assessing the degree to which? these techniques have been applied and what investment in staff and equipment and in theis organization of specialized care units has been made $\vec{\sigma}$

The contribution of the prophylactic programme has so far been small, adding only marginatty to the improvements of the 13-year period, perhaps to the extent of 3 to $6 \%$ of the total declipe $\mathbb{8}$ Nevertheless there can be little doubt that an effect is now apparent and that the rate of decline $\frac{0}{8}$ the stillbirth rate at early birth ranks HasD accelerated since about 1970 . Although the tegi $-\overrightarrow{0}$ niques of prevention were developed early in thes period, shortage of the necessary material was steh that in 1967, for example, there was only enough material to treat about $5 \%$ of all Rh-negative women with $\mathrm{Rh}$-positive fetuses or, alternatively $12 \%$ of primiparous women of this type. Up to $1968 \%$ indeed, most of the experimental work had related only to women in whose circulations fetal cells could be demonstrated (Clarke, 1967) and earlys developments seem to have been based upon the hope that the disease could be controlled on the basis of a selective technique of this kind These hopes were shown to be without foundations in 1968 on the basis of computer simulation techniques (Knox and Walker, 1968) which. showed that the most that could reasonably be hoped for would be a reduction in incidence of abouk $15 \%$; a non-selective policy based upon theo treatment of all $\mathrm{Rh}$-negative women delivered of Rh-positive/ABO homospecific infants, at anyo parity, would be necessary.

There is no evidence that the results of the computer simulations were in fact heeded and if is not clear what evidence was used to conclude ț that treatments tested in women with substantiab postpartum complements of fetal cells in their circulations, would be effective in women who did not demonstrate a transplacental transfusion 
Direct evidence on this point was not available until 1973 (Medical Research Council Working Party, 1974). Nevertheless prophylactic treatment was increasingly applied as increasing amounts of anti-D (Rho) immunoglobulin became available. Universal treatment was recommended to the NHS by the Department of Health and Social Security in May 1971 when previous restrictionsmainly in terms of parity-were removed, although the (revised) DHSS memorandum stating this policy did not appear until 1974.

As for the future, the problems of the present analysis do not suggest that separating the effects of the components of the programme will become easier. The prophylactic programme will itself almost certainly enter a period of diminishing returns, when the separation of its effects from the improved care of the affected fetus will become more difficult. Parity-distributed stillbirth rates are likely to provide a less effective basis for this discrimination, and the time taken to produce data based upon death and stillbirth certificates is a further hindrance. As the incidence and mortality become less, it will be increasingly difficult for individual regions to monitor their own progress in relation to national standards. The control of haemolytic disease is therefore probably leaving the stage where a series of regional schemes was adequate, and the need is appearing for a nationally agreed and readily accessible information and monitoring system to relate incidence and outcome to birth rank, genotype, race, and the types of treatments applied.
Requests for reprints: Professor E. G. Knox, Health Services Research Centre, Department of Social Medicine, The Medical School, Edgbaston, Birmingham B15 2TJ.

I thank Dr W. d'A. Maycock for providing the material for Table VI and for his help in tracing policy developments in the United Kingdom. I also thank Dr A. Adelstein for allowing me to see the most recent material on stillbirths.

\section{REFERENCES}

Clarke, C. (1967). Prevention of $R h$. haemolytic disease. Brit. med. J., 4, 7.

KNox, E. G. (1968). Obstetric determinants of rhesus sensitisation. Lancet, 1, 433.

and WALKER, W. (1968). A working population model for haemolytic disease of the newborn. Arch. Dis. Childh. 43, 562.

MAYcock, W. D'A. (1975). Personal communication.

Medical Research Council Working Party (1974). Controlled Trial of Various Anti-D Dosages in Suppression of Rh. Sensitization Following Pregnancy. HMSO, London.

Office of Population Censuses and Surveys and Department of Health aNd Social Security (1962-1972). Report on the Hospital Inpatient Enquiry. HMSO, London.

Registrar General (1962-1973). Annual Statistical Reviews Quarterly Returns and Supplements on Abortion. HMSO, London. 